\title{
Measuring Library Audio-Visual Activities
}

$\mathrm{T}$ HIS PAPER will discuss the measurement of library activities with special reference to audio-visual materials. ${ }^{1}$ It will do this, first, by placing the subject in its proper setting with a discussion of the contribution of measurement to library administration, and second, by discussing certain problems of measurement in libraries especially as they relate to audio-visual activities. Much of the latter discussion is based upon the experiences of the ACRL Committee on Audio-Visual Work in $1952^{2}$ and again in $1955^{3}$ in attempting to collect data on audio-visual activities in American colleges and universities.

\section{Measuring Library Activities}

The types of problems encountered when attempting to measure audio-visual activities are similar to those met in trying to measure other library activities. Problems which arise in measuring annual expenditures for films are much the same as those encountered when measuring expenditures for binding or for magazines. Certain statements can be made concerning these general problems of library measurement which apply also to the measurement of audio-visual services.

\footnotetext{
1 The author would like to acknowledge the helpful ad. vice of Fleming Bennett, Dale Bentz, and Budd Gambee in preparing this article.

${ }^{2}$ Fleming Bennett, "Audio-Visual Services in Colleges and Universities in the United States," CRL, XVI (1955), pp. 11-19. For this survey a special questionnaire was mailed in 1952 to all colleges on the ALA Publishing Department mailing list, 1726 in all.

"John F. Harvey, "ACRL A-V'Statistics, 1954-55," (Unpublished manuscript, 1956), 3p. For this survey'a fourth page of questions was attached to the annual ACRL statistics questionnaire and mailed in the summer of 1955 .
}

Dr. Harvey is librarian, State Teachers College, Pittsburg, Kansas.
This discussion should begin with the statement that all measuring of library activities - collecting statistics on use, expenditures, size of collection, etc.-is not essential to library service. Excellent service may be given without measuring anything or collecting any statistics. No doubt many libraries have done this, so for a library association as well as for a library such an activity may be regarded as a luxury.

\section{Purpose of Measurement}

Even though it is not an essential operation, measurement is defensible on a logical basis if it will contribute toward improved library service. In fact, any activity can be defended logically if it will improve service, though its cost should be commensurate with results.

No other defense of measurement is acceptable. Collection of statistices to satisfy the librarian's curiosity or because the routine has been carried on for many years is not defensible. Each series of statistics now being collected should be evaluated carefully in the same manner as a series newly contemplated. Both chief librarians and association committee members should ask such questions as: Does the use of the figures in connection with improved service justify their collection, both kind of use and amount? Are the service needs being served legitimate, or important, or is the project costing more than it is worth?

Another important consideration is that the library must have some need for improving service in an area before it is justified in collecting statistics related to it. This may seem to be an obvious generalization, but many librarians collect statistics without fully realizing the im- 
plications of the connection between the activity and service.

\section{Careful Description Necessary}

After an area of weakness has been discovered and the librarian has decided that collecting statistics will aid in improving the situation, then this area of weakness must first be described clearly. This is often difficult. It is difficult to determine which type of audio-visual material is not being circulated, to isolate the subject field and that part of the faculty and student body not participating, and to describe the situation so that proper understanding of it can be reached.

In order to understand the performance of a library department and to describe it in some detail, it is necessary to measure it carefully in meaningful terms. Data collection thus becomes important as a tool with which to learn more about the situation and can lead to the thorough understanding on which logical decisions can be based.

\section{Comparison with a Standard}

Once information on a situation is available, in order to evaluate this situation the pertinent information should be compared with a suitable standard. Setting up such a standard will probably prove the most difficult part of the procedure. Standards are not available in all areas of library service and of the ones we have many are merely averages or else goals to shoot at.

In lieu of generally recognized standards, there are several alternatives. Comparison of the various departments within a library can prove helpful if sufficient care is taken to recognize their differences. Comparison of one department's performance over several years is usually even more helpful. Comparison with the same department in another, similar library can be useful to the extent that the two departments have comparable goals.
Many different standards can be used and they can be expressed in several different terms. Film use per student, film expenditures per student, record circulation per student credit hour of enrollment, and departmental expenditures per circulation charge for audio-visual materials are just a few of the approaches to measurement in terms allowing comparison with other libraries and with possible standards.

\section{When to Collect Data}

After measurements have been made and a sufficient amount of data collected to allow a full description of the situation the librarian may be able to stop measuring until he has decided what method of improvement to use. There is no need to continue collecting data after enough information is available to establish the picture-no need to prove again what is known already. In other cases, however, continuous data collection will be desirable. Then, after the method of improvement has been applied, in many cases data can again be collected to see if any improvement in results has occurred.

\section{Problems of \\ Audio-Visual Measurement}

This section will discuss several problems of data collection on audio-visual activities. Certain of these problems relate to the ACRL mail questionnaire, others to data collection within the individual library, and still others equally to both, but all were met with or implied in the recent ACRL collection of audiovisual statistics and should be anticipated by others attempting to collect data in this field.

\section{Purposes of Audio-Visual Statistics}

A list of possible reasons for collecting audio-visual data is in order here:

1. Information may be needed for reports required by the local college president, college budget officer, public relations 
officer, by the regional accrediting association, or by ACRL. Of course, such information should be collected only if it can be used to improve library service, but in these situations the local librarian has little control over the decision to request the data.

2. Information may be needed by the librarian for comparison with performance standards for operations suspected to need improvement.

3. Information may be collected for a reading, viewing, and listening record for each student. Such a record would be valuable in counseling and in placement.

Probably any one of these reasons would be sufficient to make data collection desirable.

\section{A Complete Return}

Obtaining a complete return from all libraries with a mail questionnaire is one of the most difficult problems for an association committee to solve. Getting complete figures in the individual library is often surprisingly difficult, too. In the 1952 survey of the ACRL Committee on Audio-Visual Work, only 34 per cent returned completed questionnaires, a percentage so small that few conclusions for the entire group could be derived from the data. About the same ratio returned correctly completed forms in the survey undertaken in 1955.

Including a stamped and self-addressed envelope with the information form and sending a follow-up letter some time after the first wave of returns is received are helpful procedures in securing a complete return. It is important also that the questionnaire contain a full explanation of the need for the information-audiovisual or otherwise-who is collecting it: and how its collection will benefit libraries. No attempt should be made to collect data already available elsewhere.

Not only is a problem presented by incomplete returns, but also there is need to have forms completed in their entirety without questions being omitted. The problem is often seen in the individual library where incomplete record keeping hinders analysis of library problems. Returns from the 1955 audio-visual questionnaire were quite incomplete in terms of forms completed properly. Some librarians apparently failed to see this page of the questionnaire, since they left it blank; others thought it was not important and threw it away; still others completed half of it and stopped; and many others reported contradictory figures.

Several procedures may be recommended as helpful in achieving complete reporting. To reduce chances of misunderstanding, the information form should contain clear definitions of the technical terms used. For instance, a film and a record should be defined on audiovisual surveys. No valid comparisons can be made with the data unless all respondents understand all questions in the same way. Also, units used in reporting must be the same as those called for on the information form, or they may not be comparable to the other answers obtained. Printing these units on the form may encourage respondents to use them. Clarity of wording and logical arrangement of questions are also important, as is providing for simple answers such as a number, or "yes" or "no." And, at the end, a note should suggest that the respondent check over the entire questionnaire to make sure all questions have been answered correctly.

Another way of clarifying the questionnaire's purpose to the respondent is to list all items included in the term, "audio-visual materials," as they are covered in the particular questionnaire. Such a list might include $16 \mathrm{~mm}$. and $35 \mathrm{~mm}$. motion picture films, $35 \mathrm{~mm}$. filmstrips, slides, records, maps, globes, pictures, tape and wire recordings, unexposed film, television sets, bulletin boards, microfilm, microcards, microprint, dictating 
machines, radios, and museum objects. In addition, a survey might include equipment, such as cameras, projectors, screens, and phonographs. If such a list is given, it should reduce the number of information forms returned in which the librarian reports that he has no audiovisual materials and fails to realize that such common library materials as pictures, microfilm, maps, and bulletin boards are included. This was one of the difficulties with the 1955 survey which received many reports showing no audiovisual materials in large libraries, libraries which no doubt had at least a few of these materials.

Frequently, librarians, working with a new questionnaire, do not have easily available the figures necessary for correct answers. This was one of the chief problems in the two ACRL audio-visual questionnaires. Reporting a slide collection as containing "hundreds of slides," as did one librarian, is not very helpful. Many librarians had not maintained budget and expenditure control over these activities specifically, so they could not give cost figures for audio-visual materials, maintenance, and equipment. It is useless to ask for data not readily available, and any group wishing to collect audio-visual data should either give respondents two years of advance warning and list the breakdowns desired or else collect only what is readily available.

\section{Sampling Techniques}

The use of sampling techniques can be suggested as a means of collecting data with relatively little expenditure of time. They may be used to advantage by both the association committee and the individual librarian. For example, the microfilm machine use totals obtained through taking a sample for a dozen selected weeks will often provide a good approximation of the totals which might be obtained through counting painstakingly every single usage during the year.
Several library departments should be able to obtain satisfactory estimates of total activities by sampling. For instance, it should be helpful in counting monthly book, periodical, and audio-visual charges, the number of persons using a reading room or stack area, the number of books patrons remove from shelves, the number of reference questions asked, the number of books on library shelves, the number of people viewing library film showings, attendance at children's story hours - in fact, in any situation where an exact total is not needed and where there are no large and irregular fluctuations in the accumulation of the data.

\section{The Library with No \\ Audio-Visual Materials}

On any mail information form provision should be made at the beginning for the librarian with no audio-visual materials to check, so that he need not fill in the remaining blanks. Provision for such checking and for listing all materials should enable respondents to see where they stand immediately and to complete the form properly.

Provision should also be made at the beginning for indicating whether or not the questionnaire seeks information on library audio-visual materials even though the main campus collection of these materials may be housed elsewhere. Several librarians indicated on the 1955 audio-visual survey that since the main campus collection was elsewhere, they assumed the survey was not interested in their own audio-visual holdings - an assumption which was incorrect.

The problems of measuring holdings are concerned primarily with defining what is to be measured. Which gives a truer picture of the library's holdings, the number of volumes held or the number of titles? The number of reels of film, film titles, or prints? The number of albums, records, titles, or slides? 
In general it is reasonable to count audio-visual materials in the same manner as printed materials are counted. If the library counts books by title, then it should count films and records by title; if by volumes, as do most libraries, then by reel and record.

At any rate, in collecting data on holdings, the unit should be specified and results asked for in the same units from all libraries.

Librarians occasionally try to measure the caliber of holdings by using a checklist, but more often they are content with determining the size of holdings. The exact significance of size is not clear, but no doubt it is thought to be related to caliber. Where a sufficiently comprehensive checklist can be checked, one which is well adapted to the needs of the particular library, this should be the best means of measuring a book, periodical, film, or record collection; but few such lists have ever been compiled.

\section{Measuring Expenditures}

In order to show expenditures in meaningful categories it is necessary to organize the library's financial records to reveal this information. This will often require keeping financial records in considerable detail. For instance, in order to ascertain the extent to which film and filmstrip collections are being built up to serve the school of medicine, it may be desirable to know the film and filmstrip expenditures in that area both before and after the build-up was started. These expenditures are of little value unless they can be compared over a period of several years and also with expenditures of other libraries collecting film and filmstrip material for the same purpose.

The units in which expenditures should be obtained provide no room for difference of opinion, all being expressed in dollars. Other helpful breakdowns, however, might call for dollars spent on audio-visual materials per student credit hour of enrollment in medicine or audiovisual circulation charges in medicine per dollar spent for audio-visual materials.

\section{Measuring Use}

The difficulties of measuring library use are great and will be dealt with only briefly. The most important problem is not how many pictures or books go out the door, but their impact on the library community. It is very difficult to measure impact on the community, i.e., the extent to which education and recreation are improved over what they might be without the library, but the point is that measuring circulation charges is only a crude and indirect method of gauging this impact. It measures the fact that the patron charged out a picture, not that he looked at it or that it had an effect on him. We now measure only what should lead to positive results, not the results themselves.

In measuring use of audio-visual materials there are several problems peculiar to the kind of material. For instance, should use be measured according to the number of films and records charged out, by the number of persons to whom these films and records were shown or played, or by the number of times they were shown or played? Since there is now no good way of measuring directly the impact of films and records on patrons, librarians should try to measure it indirectly as accurately and completely as possible. This suggests measuring the entire number of people who saw the film or heard the record, though this is more difficult than merely counting the number of times it was charged out.

Another problem is caused by the differences from campus to campus in methods of promoting and circulating such material. In one library home circulation of records may be promoted while in another it may not be allowed. The best that might be done with figures of use is to group the departments with like 
treatment of materials and avoid comparisons between unlike departments wherever possible.

\section{Analyzing the Data and Interpreting Results}

Interpreting the results of any data collection should be relatively easy if it has been set up properly. However, the questioner, reporter, and analyzer must all three have understood the questionnaire, its purpose and procedure in the same way; otherwise the data cannot be analyzed correctly and the conclusions will not be valid. Results can often be put into tables and frequency charts which will bring out the relationships of the data. It should usually be a question of whether or not the data show expected results, since data will usually be collected to prove or disprove one or more hypotheses or to be compared with a performance standard. But care must always be taken to carry out careful, scientific analysis of data, or conclusions will be biased.

What analyses of audio-visual data are likely to be helpful and meaningful and to be worth the effort made to collect them? Of course, the answer to this question as to so many others depends on the local situation. But several breakdowns may be suggested as having potential value. These breakdowns may be divided into those showing a potential for service and those showing service given.

In order to evaluate the potential for service it may be desirable to obtain figures representing the total number of materials, broken down by type as seems necessary, the total pieces of equipment. as well as the expenditures for new materials, new equipment, and equipment repair, and the items which were newly acquired in these categories. With student enrollment figures, the librarian can then work out ratios showing the number of materials available per student, expenditures per student, and other potentials for service, which may be com- pared with figures from other campuses or other parts of the library. They will be more meaningful in showing how well prepared the library is to give good service if broken down by subject, by department, or by school of the institution.

To show service, the usual use figures are necessary, broken down by kind of material or service and again by department or school of the institution if they are to be more meaningful.

With such figures the librarian can study potential, the extent to which potential is being realized, and, further, can identify the weak and strong areas in the operation. For instance, the record collection may be found to rank first in the region, or perhaps filmstrips are being used at a high rate per student enrolled per title available; but the fact that pictures are not being used, suggests the need of either budgetary changes in audio-visual acquisitions or else more intensive promotional activities. Again, physical education may be using filmstrips heavily per student credit hour of enrollment, but biology may, not.

Furthermore, cost analyses can be made which, when compared with analyses in other libraries, will suggest whether or not the library is paying too much for the level of service provided. Such analyses are often made in terms of unit costs. For example, is the acquisitions cost per film significantly higher in Library $\mathrm{A}$ than in a representative sample of similar libraries? Or, in such a situation, is the annual repair cost per piece of audio-visual equipment higher than the average? Or is the cost per recording circulated higher than it is in comparable libraries? Such unit cost analyses can be used to identify areas of operation needing careful procedure analysis leading to work simplification.

\section{Conclusion}

This has been an attempt to describe the various problems which confront a (Continued on page 204) 